\title{
A multicenter retrospective comparison of goniotomy versus trabecular bypass device implantation in glaucoma patients undergoing cataract extraction
}

This article was published in the following Dove Press journal:

Clinical Ophthalmology

\author{
Syril K Dorairaj' \\ Malik Y Kahook ${ }^{2}$ \\ Blake K Williamson ${ }^{3}$ \\ Leonard K Seibold ${ }^{4}$ \\ Mohammed K ElMallah ${ }^{5}$ \\ Inder $\mathrm{P}$ Singh ${ }^{6}$ \\ On behalf of the KDB \\ Goniotomy Study Group \\ 'Department of Ophthalmology, \\ Mayo Clinic, Jacksonville, FL, ${ }^{2}$ School \\ of Medicine, University of Colorado, \\ Denver, CO, ${ }^{3}$ Williamson Eye Center, \\ Baton Rouge, LA, ${ }^{4}$ School of Medicine, \\ University of Colorado, Aurora, CO, \\ ${ }^{5}$ Ocala Eye, Ocala, FL, ${ }^{6}$ The Eye Center \\ of Racine and Kenosha, Kenosha, \\ WI, USA
}

Purpose: The aim of this study was to compare intraocular pressure (IOP) outcomes in eyes with cataract and glaucoma undergoing phacoemulsification (phaco) in combination with goniotomy using the Kahook Dual Blade (KDB) or implantation of a single iStent trabecular bypass device. Methods: Retrospective analysis of IOP and IOP-lowering medication reduction in eyes undergoing phaco-goniotomy with KDB $(n=237)$ or phaco-iStent $(n=198)$. Preoperative, intraoperative, and postoperative data were collected through 6 months of follow-up. Outcome measures included mean IOP reduction, mean reduction in IOP-lowering medications, and the proportion of eyes achieving $\geq 20 \%$ IOP reduction or $\geq 1$ medication reduction from baseline.

Results: Mean IOP in the phaco-goniotomy with KDB group decreased from $17.9 \pm 4.4 \mathrm{mmHg}$ at baseline to $13.6 \pm 2.7 \mathrm{mmHg}$ at Month $6(P<0.001)$, with mean medication use decreasing from $1.7 \pm 0.9$ to $0.6 \pm 1.0(P<0.001)$. In the phaco-iStent group, mean IOP decreased from $16.7 \pm 4.4 \mathrm{mmHg}$ to $13.9 \pm 2.7 \mathrm{mmHg}(P<0.001)$, with mean IOP-lowering medication use decreasing from $1.9 \pm 0.9$ to $1.0 \pm 1.0(P<0.001)$. Mean IOP reduction from baseline was significantly greater in the phaco-goniotomy with KDB group at Month 6 (phaco-goniotomy with $\mathrm{KDB}-4.2 \mathrm{mmHg}$ [23.7\%] vs phaco-iStent $-2.7 \mathrm{mmHg}$ [16.4\%]; $P<0.001)$. IOP-lowering medication reduction was greater in the phaco-goniotomy with KDB group compared to the phaco-iStent group ( 1.1 vs 0.9 medications, respectively; $P=0.001$ ). The most common adverse event was IOP spikes occurring in $12.6 \%$ of phaco-iStent eyes and $6.3 \%$ of phaco-goniotomy with KDB eyes $(P=0.024)$.

Conclusion: Goniotomy with the KDB combined with cataract surgery significantly lowers both IOP and the need for IOP-lowering medications compared to cataract extraction with iStent implantation in glaucomatous eyes through 6 months of postoperative follow-up.

Keywords: glaucoma, goniotomy, intraocular pressure

\section{Introduction}

Cataract and glaucoma are age-related ocular conditions that together cause the majority of blindness worldwide. ${ }^{1}$ For glaucoma patients with visually significant cataract, elective cataract surgery represents an opportunity to simultaneously improve vision, as well as lower intraocular pressure (IOP). Traditional glaucoma surgeries have included trabeculectomy and tube-shunt procedures. These procedures are effective and can be combined with cataract surgery, but their safety profiles may preclude their use in some patients, especially those with mild-to-moderate glaucomatous disease not requiring large decreases in pressure..$^{2,3}$
Correspondence: Syril K Dorairaj Department of Ophthalmology, Mayo Clinic, 4500 San Pablo Road, Jacksonville, FL 4776, USA

Tel +l 9049532000

Email syrildorairaj@gmail.com $\mathrm{BY}$
hC for commercial use of this work, please see paragraphs 4.2 and 5 of our Terms (https://www.dovepress.com/terms.php). 
More recently, a family of microinvasive glaucoma surgeries (MIGS) has been developed with the goal of providing IOP reduction more safely than with bleb-based surgical procedures. Many of these procedures bypass the obstructed trabecular meshwork (TM) and facilitate aqueous humor outflow into Schlemm's canal while others bypass the conventional outflow system by way of suprachoroidal stents. ${ }^{4,5}$ Many of the existing MIGS devices are approved as a concomitant procedure with cataract extraction and have been compared to standalone cataract surgery in eyes with mild-to-moderate glaucoma. ${ }^{6,7}$ Due to the infancy of many of the devices belonging to the MIGS category or similar ab interno glaucoma interventions, there are few robust comparative studies that evaluate the efficacy and safety of these approaches.

Two trabecular-based procedures are goniotomy performed using the Kahook Dual Blade (KDB) (New World Medical, Rancho Cucamonga, CA, USA) and implantation of an iStent trabecular bypass device (Glaukos, San Clemente, CA, USA). The KDB is a class I FDA registered single use ophthalmic knife designed to perform a goniotomy through precise excision of a strip of TM via an ab interno approach through a clear corneal incision. The instrument has a distal tip that pierces the TM, enters Schlemm's canal, and as it is advanced along the trajectory of the canal, elevates and guides the TM up a ramp and toward two parallel blades that excise a full strip of TM leaving a clear path for aqueous to drain into the collector channels and distal outflow system. ${ }^{8}$ Thus, goniotomy, using the $\mathrm{KDB}$, restores aqueous outflow through the conventional aqueous outflow system.

The iStent is a snorkel-shaped heparin-coated titanium device designed to be inserted through the TM and also via an ab interno approach through a clear corneal incision, so that its long arm rests within Schlemm's canal and its short arm traverses the TM and allows aqueous humor to enter from the anterior chamber, through the device and into Schlemm's canal. The iStent is approved by the US FDA only combined with cataract surgery. In a clinical trial, cataract surgery with iStent implantation lowered IOP and reduced reliance on IOP-lowering medications more than cataract surgery alone. ${ }^{9}$

The current study is a retrospective comparison of the efficacy and safety of goniotomy performed with the KDB versus implantation of the iStent trabecular bypass device, in glaucomatous eyes with mild-to-moderate disease also undergoing elective cataract surgery. The goal of the study is to determine the reduction of both IOP and IOP-lowering medication in eyes undergoing these two procedures.

\section{Methods}

This was a retrospective analysis of data collected from the medical records of patients with glaucoma undergoing elective phacoemulsification (phaco) cataract surgery combined with goniotomy either with KDB (phaco-goniotomy with KDB group) or with iStent implantation (phaco-iStent group). A de-identified data set was analyzed. Due to its retrospective nature, the study was granted a waiver of informed consent from a central ethics committee (Sterling IRB).

Data were contributed by 14 surgeons in the USA and one surgeon in Mexico. Surgeons participating in this study were experienced with the use of both goniotomy with the KDB and implantation of the iStent device. Data were collected from subjects aged 18-89 years diagnosed with mild-tomoderate glaucoma defined by International Classification of Diseases 9 definitions (ICD-9 codes 365.71 and 365.72, respectively) whose IOP was controlled with one or more topical IOP-lowering medications. Data were collected from one or both eyes of each eligible subject. Qualifying eyes must have undergone uncomplicated phaco and posterior chamber intraocular lens (PCIOL) implantation along with goniotomy either using the KDB or implantation of a single iStent device. Only subjects with complete follow-up as per the protocol described below were included. Eyes were excluded if they had ocular comorbidities that reduced potential postoperative best-corrected distance visual acuity (BCDVA); if cataract surgery was complicated by vitreous loss, vitrectomy, or IOL implantation in the sulcus or the anterior chamber; or if the eye had undergone any prior incisional glaucoma surgery.

Surgical procedures and postoperative care were at each investigator's discretion and adhered to accepted standards of care. In these patients undergoing elective phaco, the rationale for adding a glaucoma procedure was to achieve a lower IOP, to reduce reliance on medications, or both. Cataract surgery was performed using phaco with or without femtosecond laser assistance. The choice of goniotomy with $\mathrm{KDB}$ or iStent was at each investigator's discretion, and each procedure was performed as recommended by the respective manufacturers along with completion of the cataract and PCIOL implantation procedure. Data were collected from preoperative (baseline) visits attended in the 6 weeks preceding surgery, the operative visit, and postoperative visits on Day 1, Week 1, and Months 1, 3, and 6. Data included demographics, preoperative glaucoma status, IOP, IOP-lowering medications, and visual acuity at each time point. IOP was measured using Goldmann applanation tonometry, and distance visual acuity was measured using the Snellen acuity chart at the $20 \mathrm{ft}$ equivalent distance under mesopic lighting.

The primary efficacy end point was reduction of IOP $\geq 20 \%$ from baseline or reduction of IOP-lowering medications $\geq 1$ from baseline. These efficacy outcomes were compared between treatment groups using mixed 
model techniques, with Bonferroni's method utilized to address multiple testing. The significance threshold was set at 0.05 . Safety end points included postoperative BCDVA, the incidence of ocular adverse events, and the incidence of secondary surgical interventions. Descriptive data are presented. This was designed as a descriptive study rather than to test a specific hypothesis; therefore, no formal power calculations were conducted a priori.

\section{Results}

Data were collected from a total of 435 eyes of 318 subjects, 237 eyes in the phaco-goniotomy with KDB group and 198 eyes in the phaco-iStent group. Baseline demographic and glaucoma status data are given in Table 1. There were statistically significant differences between groups in the distributions of ethnicity ( $P=0.038$, with more Caucasians in the phacoiStent group and more Hispanics in the phaco-goniotomy with KDB group) and type of glaucoma $(P<0.001$, with more primary open-angle glaucoma in the phaco-iStent group and more angle-closure glaucoma in the phaco-goniotomy with KDB group). These differences in demographics were not considered to have a meaningful impact on study outcomes.

\section{IOP reduction}

Mean IOP data for each group at each time point is given in Table 2 and Figure 1. Mean baseline IOP in the phaco-goniotomy with KDB group was $17.9 \pm 4.4 \mathrm{mmHg}$.

Table I Baseline demographic and glaucoma status data

\begin{tabular}{|c|c|c|c|}
\hline & $\begin{array}{l}\text { Phaco- } \\
\text { goniotomy } \\
\text { with KDB } \\
(\mathrm{N}=237)\end{array}$ & $\begin{array}{l}\text { Phaco-iStent } \\
(\mathrm{N}=198)\end{array}$ & $P$-value \\
\hline Age (years), mean $\pm S D$ & $70.1 \pm 8.9$ & $71.3 \pm 8.1$ & 0.169 \\
\hline \multicolumn{4}{|l|}{ Gender, n (\%) } \\
\hline Female & 145 (6I.2) & $\mathrm{II} 2(56.6)$ & 0.330 \\
\hline Male & $92(38.8)$ & $86(43.4)$ & \\
\hline \multicolumn{4}{|l|}{ Ethnicity, n (\%) } \\
\hline Caucasian & $110(46.4)$ & $119(60.1)$ & 0.038 \\
\hline Hispanic & $63(26.6)$ & $34(17.2)$ & \\
\hline Black & $42(17.7)$ & $34(17.2)$ & \\
\hline Asian & $14(5.9)$ & $7(3.5)$ & \\
\hline Others & $8(3.4)$ & $4(2.0)$ & \\
\hline \multicolumn{4}{|l|}{ Glaucoma type, n (\%) } \\
\hline Primary open-angle & I $78(75.1)$ & I 77 (89.4) & $<0.001$ \\
\hline Exfoliation & $17(7.2)$ & $3(1.5)$ & \\
\hline Pigmentary & $15(6.3)$ & $4(2.0)$ & \\
\hline Angle closure & $14(5.9)$ & $0(0.0)$ & \\
\hline Normal tension & $6(2.5)$ & $4(2.0)$ & \\
\hline Congenital & I (0.9) & $0(0.0)$ & \\
\hline Others & $6(2.5)$ & $10(5.1)$ & \\
\hline \multicolumn{4}{|l|}{ Severity, n (\%) } \\
\hline Mild & $117(49.4)$ & $85(49.1)$ & 0.095 \\
\hline Moderate & $120(50.6)$ & $88(50.9)$ & \\
\hline
\end{tabular}

Abbreviations: KDB, Kahook Dual Blade; phaco, phacoemulsification.
Statistically significant reductions in IOP from baseline were seen at each of the five postoperative time points ( 1 day, 1 week, and 1, 3, and 6 months), ranging from $-2.3 \mathrm{mmHg}$ to $-4.3 \mathrm{mmHg}(13 \%-24 \% ; P<0.001)$. The mean IOP at Month 6 was $13.6 \pm 2.7 \mathrm{mmHg}$, a $4.2 \mathrm{mmHg}$ (24\%) reduction from baseline $(P<0.001)$. Across the five postoperative time points, IOP reductions of $\geq 20 \%$ from baseline were seen in $40.9 \%-56.1 \%$ of eyes (Figure 2).

In the phaco-iStent group, the mean IOP at baseline was $16.7 \pm 4.4 \mathrm{mmHg}$ and over the five time points were reduced by $0.2-2.7 \mathrm{mmHg}$ (Table 2 and Figure 1). Statistically significant IOP reductions were only achieved at Months 1,3 , and 6 time points $(P<0.001$ at each). The mean IOP at Month 6 was $13.9 \pm 2.7 \mathrm{mmHg}$, a $2.7 \mathrm{mmHg}(16.4 \%)$ reduction from baseline $(P<0.001)$. Across the five postoperative time points, IOP reductions of $\geq 20 \%$ from baseline were seen in $24.2 \%-43.9 \%$ of eyes (Figure 2).

Mean IOPs were statistically similar in both groups at all time points. Analysis of percent change in IOP from baseline identified statistically significant greater reduction in the phaco-goniotomy with KDB group versus in the phaco-iStent group at all postoperative time points $(P<0.001)$. Additionally, the proportion of eyes achieving IOP reduction $\geq 20 \%$ (Figure 2) was statistically greater in the phaco-goniotomy with KDB group than in the phaco-iStent group at every time point after Day $1(P \leq 0.011)$.

\section{Medication reduction}

IOP-lowering medication use in each group at each time point is given in Table 3 and Figure 3. At baseline, the average number of IOP-lowering medications used in the phaco-goniotomy with KDB group was $1.7 \pm 0.9$. Throughout follow-up, this was significantly reduced at every time point $(P<0.001)$, and by Month 6, the mean number of medications used was $0.6 \pm 1.0$, a mean reduction of 1.1 medications (63\%). Across the five postoperative time points, the proportion of eyes in which the IOP-lowering medication regimen was reduced by one or more medications ranged from $44.3 \%$ to $77.6 \%$ (Figure 4 ).

In the phaco-iStent group, IOP-lowering medication use was also significantly reduced at every time point $(P<0.001)$, from a baseline mean of $1.9 \pm 0.9$ to $1.0 \pm 1.0$ medications at Month 6 (a mean reduction of 0.9 medications [46\%]; $P<0.001)$. Across the five postoperative time points, the proportion of eyes in which the IOP-lowering medication regimen was reduced by one or more medications ranged from $42.4 \%$ to $64.1 \%$ (Figure 4 ).

Mean IOP-lowering medication reductions from baseline were statistically significantly different between treatment groups at Months 1, 3, and 6 time points $(P<0.001)$. Also, at 
Table 2 Mean intraocular pressure values at each time point for both treatment groups $(\mathrm{mmHg})$

\begin{tabular}{|c|c|c|c|c|c|c|c|c|c|}
\hline \multirow{2}{*}{$\begin{array}{l}\text { Time } \\
\text { point }\end{array}$} & \multicolumn{4}{|c|}{ Phaco-goniotomy with KDB } & \multicolumn{4}{|c|}{ Phaco-iStent } & \multirow{2}{*}{$\begin{array}{l}P \text {-value (difference } \\
\text { in \% change from } \\
\text { baseline between } \\
\text { groups) }\end{array}$} \\
\hline & $\mathbf{N}$ & $\begin{array}{l}\text { Mean } \\
\text { (SD) }\end{array}$ & $\begin{array}{l}\text { Change from } \\
\text { baseline (mean } \\
\text { difference in \% } \\
\text { change) }\end{array}$ & $\begin{array}{l}\text { P-value } \\
\text { (change } \\
\text { from } \\
\text { baseline) }\end{array}$ & $\mathbf{N}$ & $\begin{array}{l}\text { Mean } \\
\text { (SD) }\end{array}$ & $\begin{array}{l}\text { Change from } \\
\text { baseline (mean } \\
\text { difference in \% } \\
\text { change) }\end{array}$ & $\begin{array}{l}\text { P-value } \\
\text { (change } \\
\text { from } \\
\text { baseline) }\end{array}$ & \\
\hline Baseline & 237 & $17.9(4.4)$ & Reference & - & 198 & $16.7(4.4)$ & Reference & - & - \\
\hline Day I & 229 & I5.4 (5.6) & $-2.5(-13.9)$ & $<0.00 \mathrm{I}$ & 193 & $16.0(5.6)$ & $-0.7(-4.3)$ & 0.495 & $<0.001$ \\
\hline Week I & 211 & I5.6 (5.5) & $-2.3(-12.7)$ & $<0.001$ & 163 & $16.5(5.5)$ & $-0.2(-0.9)$ & 0.999 & $<0.00$ I \\
\hline Month I & 223 & $14.0(3.6)$ & $-3.8(-21.3)$ & $<0.00 \mathrm{I}$ & 163 & $14.9(3.5)$ & $-1.8(-10.6)$ & $<0.001$ & $<0.001$ \\
\hline Month 3 & 203 & $13.6(2.7)$ & $-4.3(-24.0)$ & $<0.00 \mathrm{I}$ & 128 & I4.2(2.6) & $-2.5(-15.0)$ & $<0.001$ & $<0.00 \mathrm{I}$ \\
\hline Month 6 & 237 & $13.6(2.7)$ & $-4.2(-23.7)$ & $<0.001$ & 198 & $13.9(2.7)$ & $-2.7(-16.4)$ & $<0.001$ & $<0.001$ \\
\hline
\end{tabular}

Notes: Adjusted P-values for Bonferroni corrections. “- “ indicates no change from baseline.

Abbreviations: KDB, Kahook Dual Blade; phaco, phacoemulsification; SD, standard deviation.

Week 1 through Month 6, more eyes in the phaco-goniotomy with KDB group versus the phaco-iStent group discontinued one or more IOP-lowering medications ( $P \leq 0.013)$; at Month $6,77.6 \%$ of phaco-goniotomy with $\mathrm{KDB}$ eyes versus $64.1 \%$ of phaco-iStent eyes had a reduction of at least one or more IOPlowering medications. More eyes in the phaco-goniotomy with $\mathrm{KDB}$ group than in the phaco-iStent group were IOP-lowering medication-free at Month 6 (58.6 vs 43.4\%, $P=0.002$ ).

\section{Visual acuity improvement}

Mean best-corrected visual acuity (BCVA) improved significantly, from a baseline of $0.4 \pm 0.3 \log$ MAR to $0.1 \pm 0.2$ $\operatorname{logMAR}$ at Month 6 in both groups $(P<0.001)$. Improvement in mean BCVA was noted at all visits compared to baseline BCVA. No between-group differences in BCVA change were found $(P=0.999)$.

\section{Safety}

Both procedures were safe and well tolerated. Adverse events are given in Table 4. Adverse events were generally mild to moderate in intensity and resolved spontaneously. The most common adverse event was IOP spikes (IOP increase by $\geq 10 \mathrm{mmHg}$ from baseline), occurring in 25 (12.6\%) phacoiStent eyes and 15 (6.3\%) phaco-goniotomy with KDB eyes $(P=0.024)$. Medical therapy for the IOP spike was administered to eight eyes (4\%) in the phaco-iStent group, while $10(4.3 \%)$ eyes in the phaco-goniotomy with KDB group received medical therapy. All other IOP spikes resolved spontaneously. Other common adverse events included transient corneal edema, posterior capsule opacity, transient postoperative anterior chamber inflammation, and posterior vitreous detachment.

The most common intraoperative observation was blood reflux from collector channels, which is common in all anglebased procedures and is a sign of a patent distal outflow system. As this was a retrospective review, there was no method to systematically and uniformly measure intraoperative reflux and residual blood postoperatively. Intraoperative reflux was more common in the phaco-goniotomy with KDB group likely due to unroofing and exposure of multiple collector channels compared to single iStent implantation. Beyond occurrences related to intraoperative blood reflux, persistent blood in the anterior chamber was observed at Week 1 visit in one eye $(0.5 \%)$ in the phaco-iStent group and nine eyes $(3.8 \%)$ in the phaco-goniotomy with KDB group. Only one

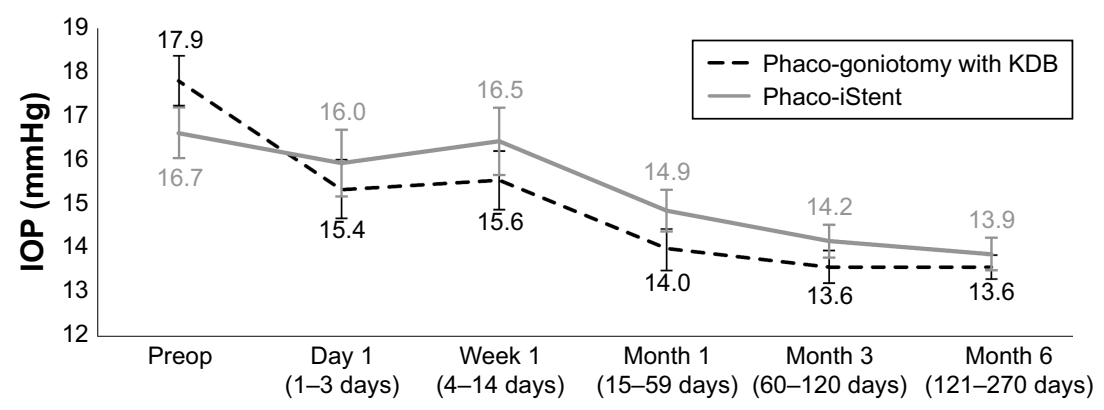

Figure I Mean with 95\% confidence interval for IOP at each time point for phaco-goniotomy with KDB and phaco-iStent groups. Abbreviations: IOP, intraocular pressure; KDB, Kahook Dual Blade; phaco, phacoemulsification; Preop, preoperative. 


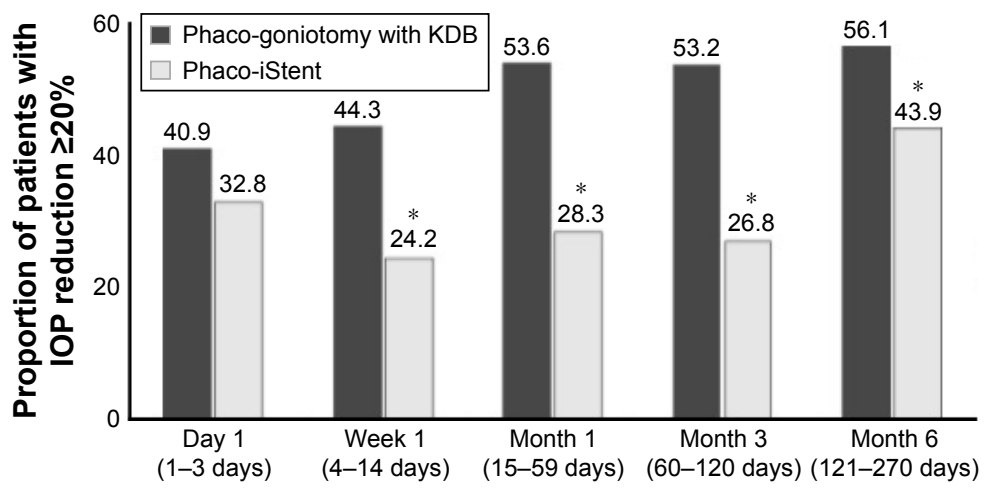

Figure 2 Proportion of patients with IOP reduction $\geq 20 \%$ from baseline at each time point.

Note: *Significant difference between both groups at an $\alpha$ of 0.05 .

Abbreviations: IOP, intraocular pressure; KDB, Kahook Dual Blade; phaco, phacoemulsification.

eye, in the phaco-goniotomy with KDB group, had residual blood at 1 month with all anterior chamber blood resolving in both groups by Months 3 and 6 .

\section{Discussion}

Common indications for adding a glaucoma procedure to an elective cataract surgery are lowering IOP or reducing reliance on IOP-lowering medications. This retrospective analysis demonstrates that phaco-goniotomy with KDB lowers IOP and reduces reliance on IOP-lowering medications in eyes with mild-to-moderate glaucoma.

The mean medicated preoperative IOP of the study sample - comprised eyes with mild or moderate glaucoma was $\sim 17.5 \mathrm{mmHg}$, suggesting that many subjects may have undergone the glaucoma portion of the combined procedure with the main goal of reducing medication burden more so than IOP itself. In this regard, the mean IOP reductions of $2.5 \mathrm{mmHg}$ observed in the phaco-iStent group and $3.8 \mathrm{mmHg}$ in the phaco-goniotomy with KDB groups are clinically significant. In a prospective interventional case series of mild-to-severe glaucoma patients undergoing goniotomy with KDB and phaco, Greenwood et $\mathrm{al}^{10}$ reported that 71 eyes had an initial mean baseline IOP of $17.4 \pm 5.2 \mathrm{mmHg}(\mathrm{SD})$, which was reduced to $12.8 \pm 2.6 \mathrm{mmHg}(P<0.001), 6$ months postoperatively. In this same trial, IOP-lowering medication use decreased from $1.6 \pm 1.3$ to $0.9 \pm 1.0(P<0.005)$. These results are similar to those reported in the present study for phaco-goniotomy with $\mathrm{KDB}$, with a trend toward a greater reduction in IOP and a slightly lower reduction in IOP-lowering medications. In the USA, pivotal iStent trial ${ }^{9}$ enrolled subjects with a mean preoperative IOP of $18.4 \mathrm{mmHg}$ using a mean of 1.5 medications (roughly comparable to the baseline values in the current study) and reported mean IOP reductions at 12 months of $1.5 \mathrm{mmHg}$ with a mean reduction in IOP-lowering medications of 1.4.

Strengths of this study include its large size (435 eyes) and that the data presented were collected in a real-world clinical setting. Another strength is the direct comparison of two angle-based glaucoma procedures when combined with cataract extraction, as such head-to-head comparisons are fundamentally lacking in currently published literature.

Table 3 Mean IOP-lowering medications used at each time point in both groups

\begin{tabular}{|c|c|c|c|c|c|c|c|c|c|}
\hline \multirow{2}{*}{$\begin{array}{l}\text { Time } \\
\text { point }\end{array}$} & \multicolumn{4}{|c|}{ Phaco-goniotomy with KDB } & \multicolumn{4}{|c|}{ Phaco-iStent } & \multirow{2}{*}{$\begin{array}{l}\text { P-value (difference } \\
\text { in \% change from } \\
\text { baseline between } \\
\text { groups) }\end{array}$} \\
\hline & $\mathbf{N}$ & $\begin{array}{l}\text { Mean } \\
\text { (SD) }\end{array}$ & $\begin{array}{l}\text { Change from } \\
\text { baseline (mean } \\
\text { difference in \% } \\
\text { change) }\end{array}$ & $\begin{array}{l}\text { P-value } \\
\text { (change } \\
\text { from } \\
\text { baseline) }\end{array}$ & $\mathbf{N}$ & $\begin{array}{l}\text { Mean } \\
\text { (SD) }\end{array}$ & $\begin{array}{l}\text { Change from } \\
\text { baseline (mean } \\
\text { difference in \% } \\
\text { change) }\end{array}$ & $\begin{array}{l}\text { P-value } \\
\text { (change } \\
\text { from } \\
\text { baseline) }\end{array}$ & \\
\hline Baseline & 237 & $1.7(0.9)$ & - & - & 198 & $1.9(0.9)$ & - & - & - \\
\hline Day I & 231 & $0.9(1.0)$ & $-0.8(-47.1)$ & $<0.001$ & 197 & $0.9(1.0)$ & $-0.9(-50.6)$ & $<0.001$ & 0.294 \\
\hline Week I & 209 & I.I (I.0) & $-0.6(-36.0)$ & $<0.001$ & 165 & $1.0(1.0)$ & $-0.9(-47.0)$ & $<0.001$ & 0.078 \\
\hline Month I & 222 & $0.6(1.0)$ & $-1.1(-64.6)$ & $<0.001$ & 164 & $1.0(1.0)$ & $-0.8(-44.6)$ & $<0.001$ & $<0.001$ \\
\hline Month 3 & 203 & $0.6(0.9)$ & $-1.1(-63.7)$ & $<0.001$ & 130 & $1.0(0.8)$ & $-0.9(-48.8)$ & $<0.001$ & 0.001 \\
\hline Month 6 & 237 & $0.6(1.0)$ & $-1.1(-62.9)$ & $<0.001$ & 198 & $1.0(1.0)$ & $-0.9(-46.1)$ & $<0.001$ & 0.001 \\
\hline
\end{tabular}

Note: "_ " indicates no change from baseline.

Abbreviations: KDB, Kahook Dual Blade; IOP, intraocular pressure; phaco, phacoemulsification; SD, standard deviation. 




Figure 3 Mean with 95\% confidence interval for IOP-lowering medications at each time point for phaco-goniotomy with KDB and phaco-iStent groups. Note: *Significant difference between both treatment groups at an $\alpha$ of 0.05 .

Abbreviations: IOP, intraocular pressure; KDB, Kahook Dual Blade; phaco, phacoemulsification; Preop, preoperative.

Its retrospective design poses several limitations. The most significant issue is the lack of randomization. Each eye underwent the operation deemed most appropriate by each respective surgeon. Additionally, while the baseline IOPs were not statistically different, the phaco-iStent group had a lower baseline IOP than the phaco-goniotomy with KDB group, thereby slightly reducing the dynamic range between the starting IOP and the episcleral pressure compared to the dynamic range for the phaco-goniotomy with KDB group. This could bias toward better outcomes and may partially explain the greater IOP reductions than in the iStent pivotal trial. ${ }^{9}$ Due to the retrospective nature of the study, there was a difference in the percentage of patients making Month 3 visit between the two groups. However, the primary end point for this study was the IOP reduction from baseline to Month 6 and differences in the specific follow-up protocols in this retrospective study should have limited effects on the primary outcome. Also, postoperative management was not protocol driven, so there were no predefined thresholds for the addition or removal of medications during the postoperative course. Finally, the primary efficacy measure was IOP, which in this study consisted of single measurement per visit - in contrast to the multiple measurements often obtained in prospective clinical trials. Mitigating this last limitation is that IOP was assessed at five different postoperative time points and reductions in IOP were consistent across these assessments. Some surgeons are experimenting with implanting two iStent devices in order to optimize the IOP-lowering effect of those devices. Comparing these double implants with goniotomy using the KDB can be examined in future studies.

\section{Conclusion}

Goniotomy with KDB combined with cataract surgery significantly lowers both IOP and the need for IOP-lowering medications through 6 months of postoperative follow-up. The phaco-goniotomy with $\mathrm{KDB}$ procedure produced $\sim 50 \%$ greater relative reductions in IOP and $35 \%$ greater relative reductions in IOP-lowering medication use compared to the phaco-iStent procedure at 6 months. Goniotomy with KDB can benefit adult glaucoma patients requiring IOP reduction, reduced reliance on IOP-lowering medications, or both, when undergoing elective cataract surgery.

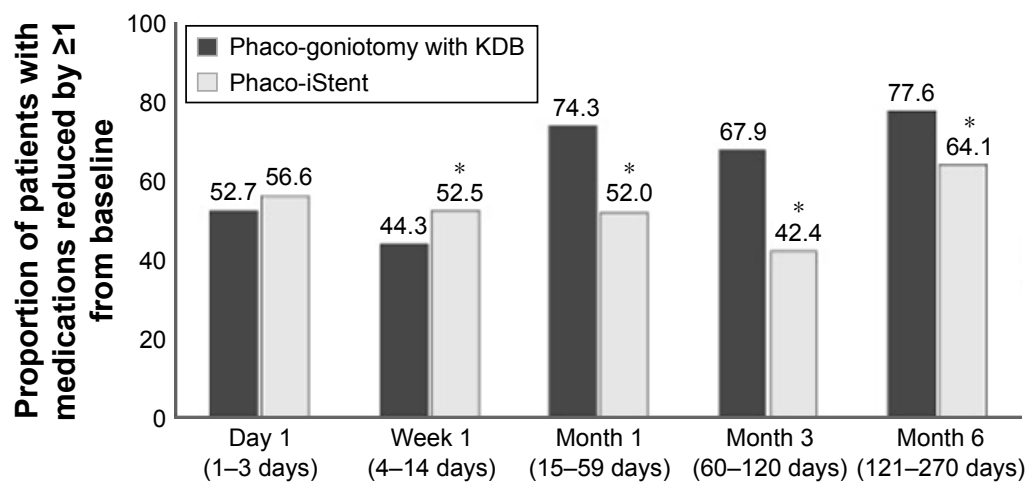

Figure 4 Proportion of patients with the number of IOP-lowering medications reduced by $\geq 1$ from baseline.

Note: *Significant difference between both groups at an $\alpha$ of 0.05 .

Abbreviations: IOP, intraocular pressure; KDB, Kahook Dual Blade; phaco, phacoemulsification. 
Table 4 Incidence of all adverse events ( $\geq 1 \%$ frequency)

\begin{tabular}{llll}
\hline Adverse event & $\begin{array}{l}\text { Phaco- } \\
\text { goniotomy } \\
\text { with KDB } \\
\text { (n=237) }\end{array}$ & $\begin{array}{l}\text { Phaco-iStent } \\
(\mathbf{n}=\mathbf{I 9 8})\end{array}$ & P-value \\
& $5(2.1 \%)$ & $3(\mathrm{I} .5 \%)$ & 0.642 \\
\hline Corneal edema & I (0.4\%) & $4(2 \%)$ & 0.116 \\
Inflammation & I (0.4\%) & $5(2.5 \%)$ & 0.060 \\
Posterior capsule opacity & $2(0.8 \%)$ & $2(1 \%)$ & 0.823 \\
Posterior vitreous detachment & $2(0.8 \%)$ & $2(1 \%)$ & 0.823 \\
Rebound iritis & I5 (6.3\%) & $25(12.6 \%)$ & $0.024 *$ \\
IOP spikes &
\end{tabular}

Note: *Significant difference between both groups at an $\alpha$ of 0.05 .

Abbreviations: KDB, Kahook Dual Blade; IOP, intraocular pressure; phaco, phacoemulsification.

\section{Acknowledgments}

We would like to thank the following for their substantial contribution in this study: Suhail Abdullah, MBSc, for significant contribution to the study design and review of article; Mark C Jasek, $\mathrm{PhD}$, for providing consultations in study design, analysis, and interpretation of data as well as critical review of the article; Khaled Bahjri, MD, MPH, $\mathrm{PhD}$, for assisting in data collection, analysis, and interpretation of findings; and Anthony Realini, MD, for assisting in writing the article. The KDB Goniotomy Study Group members include Syril K Dorairaj, MD; Gabriel S LazcanoGomez, MD; Sidney T Chang, MD; Leonard A Rappaport, MD; Mohammed ElMallah, MD; Hylton R Mayer, MD; Blake K Williamson, MD; Leonard K Seibold, MD; Ahad Mahootchi, MD; Mina B Pantcheva, MD; Sanjay N Smith, MD; Shobit Rastogi, MD; Malik Y Kahook, MD; and Inder P Singh, MD.

\section{Disclosure}

All authors have received research support from New World Medical in the past. No financial support was received for the work involved in this article. Drs Dorairaj, Kahook, Williamson, Seibold, and Singh are consultants for New World Medical. Dr Kahook receives royalties from licensed patents pertaining to the KDB. Dr ElMallah has no relevant financial disclosures. The authors report no other conflicts of interest in this work.

\section{References}

1. Congdon N, O'Colmain B, Klaver CC, et al. Causes and prevalence of visual impairment among adults in the United States. Arch Ophthalmol. 2004;122(4):477-485

2. Gedde SJ, Schiffman JC, Feuer WJ, et al; Tube versus Trabeculectomy Study Group. Treatment outcomes in the tube versus trabeculectomy (TVT) study after five years of follow-up. Am J Ophthalmol. 2012; 153(5):789.e2-803.e2.

3. Gedde SJ, Herndon LW, Brandt JD, et al; Tube Versus Trabeculectomy Study Group. Postoperative complications in the tube versus trabeculectomy (TVT) study during five years of follow-up. Am J Ophthalmol. 2012;153(5):804.e1-814.e1.

4. SooHoo JR, Seibold LK, Radcliffe NM, Kahook MY. Minimally invasive glaucoma surgery: current implants and future innovations. Can J Ophthalmol. 2014;49(6):528-533.

5. Richter GM, Coleman AL. Minimally invasive glaucoma surgery: current status and future prospects. Clin Ophthalmol. 2016;10:189-206.

6. Vold S, Ahmed II, Craven RE, et al. Two-year COMPASS trial results: supraciliary microstenting with phacoemulsification in patients with open-angle glaucoma and cataracts. Ophthalmology. 2016;123(10): 2103-2112.

7. Bacharach J. Efficacy of trabecular bypass stent through 2 years: data from the United States pivotal trial. J Cataract Refract Surg. 2014;40: 1325-1326.

8. Seibold LK, Soohoo JR, Ammar DA, Kahook MY. Preclinical investigation of ab interno trabeculectomy using a novel dual-blade device. Am J Ophthalmol. 2013;155(3):524-529.

9. Samuelson TW, Katz LJ, Wells JM, Duh YJ, Giamporcaro JE; US iStent Study Group. Randomized evaluation of the trabecular micro-bypass stent with phacoemulsification in patients with glaucoma and cataract. Ophthalmology. 2011;118(3):459-467.

10. Greenwood MD, Seibold LK, Radcliffe NM, et al. Goniotomy with a single-use dual blade: short-term results. J Cataract Refract Surg. 2017; 43(9):1197-1201.
Clinical Ophthalmology

\section{Publish your work in this journal}

Clinical Ophthalmology is an international, peer-reviewed journal covering all subspecialties within ophthalmology. Key topics include: Optometry; Visual science; Pharmacology and drug therapy in eye diseases; Basic Sciences; Primary and Secondary eye care; Patient Safety and Quality of Care Improvements. This journal is indexed on

\section{Dovepress}

PubMed Central and CAS, and is the official journal of The Society of Clinical Ophthalmology (SCO). The manuscript management system is completely online and includes a very quick and fair peer-review system, which is all easy to use. Visit http://www.dovepress.com/ testimonials.php to read real quotes from published authors. 